\title{
Effects of GnRH agonists on the expression of developmental follicular anti-mullerian hormone in varying follicular stages in cyclic mice in vivo
}

\author{
JILIANG HUANG ${ }^{*}$, XIAOYAN WANG* ${ }^{*}$ ZHILING LI, RUOWU MA and WANFEN XIAO \\ Reproductive Center, The First Affiliated Hospital of Shantou University Medical College, \\ Shantou University, Shantou, Guangdong 515041, P.R. China
}

Received August 23, 2014; Accepted June 5, 2015

DOI: $10.3892 / \mathrm{mmr} .2015 .3993$

\begin{abstract}
Gonadotrophin-releasing hormone (GnRH) agonists (GnRHa) have been widely used to induce a state of downregulation for in vitro fertilization, and its direct effects on the pituitary are well known. However, the effects of GnRHa on the expression of anti-mullerian hormone $(\mathrm{AMH})$ by follicles in varying stages in vivo remain to be fully elucidated. In the present study 84 cyclic mice were randomly divided equally into four GnRHa groups and three cyclic mice were used as a control group. The expression levels of AMH in follicles of varying stages between days 0 and 7 following GnRHa administration were quantified using immunohistochemistry. The expression of AMH in follicles at various stages revealed dynamic changes during the process of downregulation. AMH in primary follicles initially increased and then decreased gradually. In small and large preantral follicles and in granulosa cells (GCs) surrounding the oocyte of small antral follicles, the expression of AMH began to increase on day 1 , was attenuated on day 2 , and then increased to a peak. The expression levels of AMH in the GCs surrounding
\end{abstract}

Correspondence to: Professor Zhiling Li, Reproductive Center, First Affiliated Hospital of Shantou University Medical College, Shantou University, 54 Changping Road, Jinping, Shantou, Guangdong 515041, P.R. China

E-mail: stlizhiling@126.com

Abbreviations: AMH, anti-mullerian hormone; AMHRII, anti-mullerian hormone type II receptor; ANOVA, analysis of variance; ART, assisted reproductive technology; $\mathrm{COH}$, controlled ovarian hyperstimulation; FSH, follicle stimulating hormone; FSHR, FSH receptor; GCs, granulosa cells; GnRHa, gonadotrophin-releasing hormone agonist; hGCs, human granulosa cells; HGL5, human granulosa cell line; IVF, in vitro fertilization; LH, luteinizing hormone; MIS, mullerian inhibiting substance; PBS, phosphate buffer saline; PMSG, pregnant mare serum gonadotropin

*Contributed equally

Key words: gonadotrophin-releasing hormone agonist, anti-mullerian hormone, ovarian follicle, granulosa cells the basement membrane, in contrast to the GCs surrounding the oocyte, were significantly lower and did not increase on day 1. In all stages of follicles, the expression of AMH declined gradually between the peak level and last day of downregulation. On day 7, the varying follicular stages all expressed lower levels of AMH than on day 0 . This decrease was more prominent in the higher dose groups, compared with the lower dose groups. In conclusion, GnRHa was observed to induce time-dependent changes in the expression of AMH at varying follicular stages, which occurred in a dose-dependent manner.

\section{Introduction}

Anti-mullerian hormone (AMH), also termed mullerian inhibiting substance, is a dimeric glycoprotein member of the transforming growth factor- $\beta$ superfamily $(1,2)$. AMH was first detected using a radioimmunoassay in mature bovine follicular fluid (3). In females, the expression of AMH is confined to the granulosa cells (GCs) of follicles in the ovary. Its expression has been detected in the GCs of follicles in several species, including mice (4), rats (5,6), sheep (7) and humans (8). The expression of AMH begins in the primary follicles and peaks in the preantral and small antral follicles. However, the levels of AMH gradually decline during the final stages of folliculogenesis, are not expressed in primordial follicles and disappear in atretic follicles $(8,9)$.

A previous study observed that AMH can inhibit the initial recruitment of primordial follicles (10) and tumour cell proliferation (11). Other studies performed in animals have revealed that $\mathrm{AMH}$ can attenuate the sensitivity of follicles to follicle-stimulating hormone (FSH), reduce aromatase activity and the quantity of LH receptors in FSH-stimulated granulosa cells (12), and inhibit testosterone synthesis by thecal cells (13) by the binding of AMH to specific type II receptors (AMHRII) expressed in granulosa and theca cells. Previous detailed investigations have validated the use of serum AMH levels as a quantitative marker for ovarian reserve and ovarian dysfunction in in vitro fertilization (IVF) (14).

Gonadotrophin-releasing hormone (GnRH) agonist (GnRHa), a decapeptide, is similar in structure to native GnRH and binds to the GnRH receptors. Compared with native $\mathrm{GnRH}, \mathrm{GnRHa}$ has a higher affinity for GnRH receptors of 
the pituitary, higher resistance to enzymatic breakdown and a prolonged half-life, leading to its slow dissociation from GnRH receptors (15) and the concomitant desensitization of pituitary GnRH receptors. This hypogonadotropic state is referred to as downregulation (15). In the 1980s, GnRHa was experimentally introduced in the mid-luteal phase of the preceding cycle during controlled ovarian hyperstimulation $(\mathrm{COH})(16)$. By inhibiting the pituitary-ovary axis, GnRHa prevented premature luteinizing hormone ( $\mathrm{LH}$ ) surges during $\mathrm{COH}$.

The way in which the levels of $\mathrm{AMH}$ in Uthe serum change during the process of downregulation remains controversial. A previous study found that AMH levels in the sera of patients with stage II-IV endometriosis are normal 4 and 8 weeks following prolonged downregulation with goserelin administration (17). However, another report found that circulating AMH declines following the first 3 months of prolonged GnRHa treatment in girls with central precocious puberty and early puberty (18). In accordance with a GnRHa-mediated decrease in serum levels of $\mathrm{AMH}$, a reduction in the levels of AMH were observed following GnRHa treatment in premenopausal women with breast cancer (19). It has been suggested that GnRHa increases the mRNA expression of AMH in cultured human granulosa cells (hGCs) and in the human HGL5 granulosa cell line (20). By contrast, evidence implying a direct effect of GnRHa on suppression of AMH expression in the ovaries has been obtained from observations that $\mathrm{AMH}$ concentrations in follicular fluid from females treated with GnRHa are lower, compared with untreated controls (21).

Previous studies on the effects of GnRHa on the expression of AMH have all involved examination of the serum levels of AMH in vivo and GCs in vitro. The effects of GnRHa in vivo on the expression of $\mathrm{AMH}$ in follicles at varying follicular stages during downregulation remain to be elucidated. Understanding the changes of AMH in GCs can enable verification of serum $\mathrm{AMH}$ and provide evidence supporting the further utilization of serum AMH. The purpose of the present study was to investigate the effects of different doses of GnRHa administration on the expression of $\mathrm{AMH}$ at varying follicular stages during the process of downregulation in vivo.

\section{Materials and methods}

Animals. All experimental procedures in the present stduy were performed at the Experimental Animal Centre of Shantou University Medical College (SUMC; Shantou, China), according to the international ethical guidelines and with the approval of the SUMC Ethics Committee. (SUMC2013-129). Adult female KM mice (5-6 weeks old) were obtained from the Animal Center of SUMC and were housed under a 12/12 h light/dark cycle at $22-26^{\circ} \mathrm{C}$ and $50-60 \%$ humidity. All mice had free access to a standard pellet diet and water. The estrous cycles of the adult female mice were determined in vaginal smears, which were collected for 21 consecutive days. Only mice that had more than two consecutive regular 4-day cycles were used. These mice were randomly allocated into four experimental groups, with 21 mice per group, as well as a control group containing three mice.

Treatment. Treatment for downregulation involved a daily intraperitoneal injection of $\mathrm{GnRH}$ agonist (Triptorelin; Ipsen
Pharma Biotech, France) between days 3 and 9 of the estrus cycle at the following doses: $1.5 \mu \mathrm{g} / 100 \mathrm{~g}$ body weight (bw)/day, $3.0 \mu \mathrm{g} / 100 \mathrm{~g} \mathrm{bw} /$ day, $4.5 \mu \mathrm{g} / 100 \mathrm{~g}$ bw/day and (4) $6.0 \mu \mathrm{g} / 100 \mathrm{~g}$ bw/day. Control mice remained without any treatment.

Tissue collection. In each treatment group, three mice were sacrificed each day following $\mathrm{GnRH}$ agonist administration, up to day 9. The mice in the control group were sacrificed on day 0 , corresponding to day 3 of the estrus cycle. The ovaries were removed from each animal and cleaned of surrounding fat.

Immunohistochemistry. The ovaries were fixed in $4 \%$ paraformaldehyde at $4^{\circ} \mathrm{C}$ overnight and embedded in paraffin. The ovaries were then serially sectioned at a thickness of $4 \mu \mathrm{m}$. Every 10th section was used. The tissue sections between days 0 and 7 were obtained at the same time for each trial. Following dewaxing in xylene, rehydration in a series of ethanols and antigen retrieval in a microwave oven (15 min), endogenous peroxidase activity was blocked with $3 \% \mathrm{H}_{2} \mathrm{O}_{2}$ for $15 \mathrm{~min}$. To block non-specific binding sites, the sections were then incubated in $10 \%$ normal donkey serum diluted in $0.01 \mathrm{M}$ phosphate-buffered saline (PBS) for $15 \mathrm{~min}$. The sections were incubated at $4^{\circ} \mathrm{C}$ overnight with polyclonal goat anti-MIS antibody (cat. no. sc-6886, Santa Cruz Biotechnology, Santa Cruz, CA, USA), diluted 1:50 in 0.01 M PBS. The sections were then incubated for $1 \mathrm{~h}$ with secondary horseradish peroxidase (HRP)-conjugated donkey anti-goat IgG-HRP (cat. no sc-2020; Santa Cruz Biotechnology), diluted 1:100 in 0.01 M PBS. The detection of AMH was performed using chromogen, 3.3-diaminobenzidine (DAB; Gene Tech Shanghai Company Limited), according to the manufacturer's instructions. The sections were counterstained with hematoxylin, and were then dehydrated and mounted. For a negative control, the primary antibody was excluded.

Quantification of immunohistochemistry. The morphological classification of different stages of follicles were, as defined previously $(22,23)$. The follicles were distinguished as follows: Primordial follicles exhibited a single layer of flattened GCs; primary follicles exhibited a single layer of cuboidal GCs; small preantral follicles possessed between two and five layers of GCs; large preantral follicles possessed more than five layers of GCs without an antrum; small antral follicles contained fluid-filled spaces with fewer than five GC layers, and follicles with five or more layers of GCs and an antrum were considered large antral follicles. Only follicles that contained a visible oocyte with a nucleus were selected for immunohistochemical quantification.

Expression levels of AMH in follicles at different developmental stages, at different administration times and with different doses of GnRHa. For comparison of the expression levels of AMH in the control and treatment groups between days 1 and 7 (seven subgroups each day, $n=3$ per subgroup), 20 follicles of each stage in each animal were examined. For the control group (day $0 ; n=3$ ), 20 follicles of each stage in each animal were also examined. To quantify the mean density of the expression of AMH from individual follicles, analysis was performed using an image analysis system linked to an 
Olympus camera (Olympus Corporation, Tokyo, Japan). All images were captured under the same exposure times, and the mean density of each follicle was measured using Image-Pro Plus 6.0 (Media Cybernetics, Inc., Rockville, MD, USA)

Expression of AMH in the GCs surrounding the oocyte and basement membrane of small antral follicles with different doses of GnRHa. Additional analysis was performed to determine the mean density from different compartments of AMH staining within each follicle in the small antral follicles. The area of the GCs surrounding the oocyte and basement membrane were independently calculated using the same image analysis technique described above for the different follicular stages.

Statistical analysis. All data are expressed as the mean \pm standard error of the mean. Statistical analysis was performed and differences between the respective treatments performed and the control were determined using one-way analysis of variance followed by Dunnett's multiple comparison test. $\mathrm{P}<0.05$ was considered to indicate a statistically significant difference.

\section{Results}

Pattern and location of the expression of AMH during follicular development. The results of the immunohistochemistry revealed that the expression of AMH was positive in The GCs from the primary follicles and was confined to the cytoplasm (Fig. 1). The expression of AMH increased with decreasing size of the follicles. The AMH immunostaining was most marked in the preantral and small antral follicles, and was absent in the large antral follicles. In the atretic follicles and primordial follicles, no AMH was detected. At the early antral stage, AMH was predominantly present in the GCs surrounding the oocyte and in a few cells surrounding the antrum. No follicles expressed AMH in the thecal layer. Only GCs of the primary follicles exhibited homogeneous expression of AMH. Similar to the physical status, GnRHa treatment did not change the pattern of stage-specific expression of AMH or the location of expression in any of the four treatment groups. No specific immunoreactivity was observed in the negative-control ovaries.

Effects of GnRHa on the expression levels of AMH in primary follicles. Fig. 2 shows the effect of treatment with different doses of GnRHa on the expression of AMH in primary follicles. The expression of AMH expression increased initially, peaking at $\sim$ day 3 , and then declined gradually. This peak moved forward from day 4 to day 2 as the dose of GnRHa increased, with the peak $\mathrm{AMH}$ values all significantly different to those on day 0 (all $\mathrm{P}<0.05$ ). AMH decreased gradually following the peak, with no significant difference at the lowest dose (Fig. 2A). However, significant differences were observed at the highest three doses on day 7 (Fig. 2B-D).

Effects of GnRHa on the expression of AMH in small preantral follicles. In the three lower dose treatment groups, the expression of AMH increased on days 1 and 2 to a significant degree (all $\mathrm{P}<0.05$; Fig. 3). However, the highest dose treatment group caused no elevation in the level of AMH on day $1(\mathrm{P}>0.05)$,
Positive
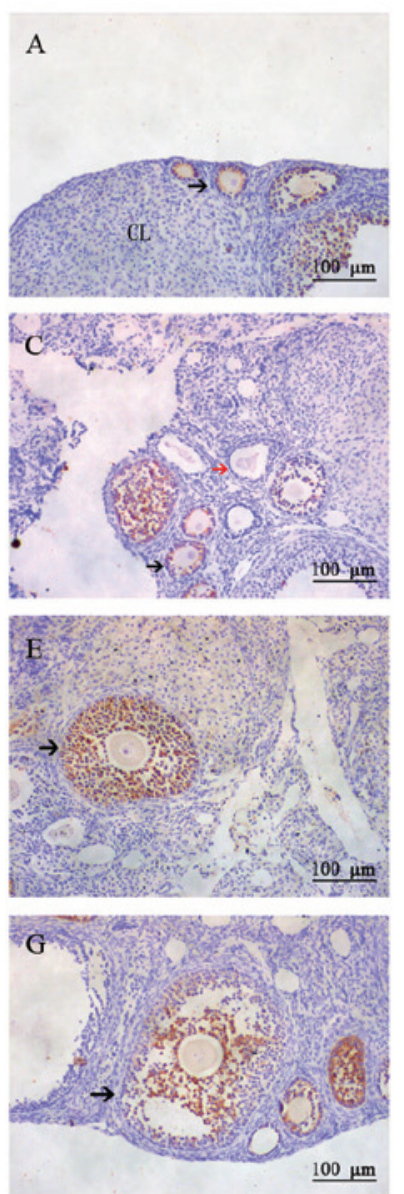

$100 \mu \mathrm{m}$

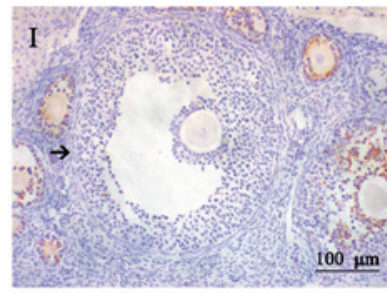

Negative
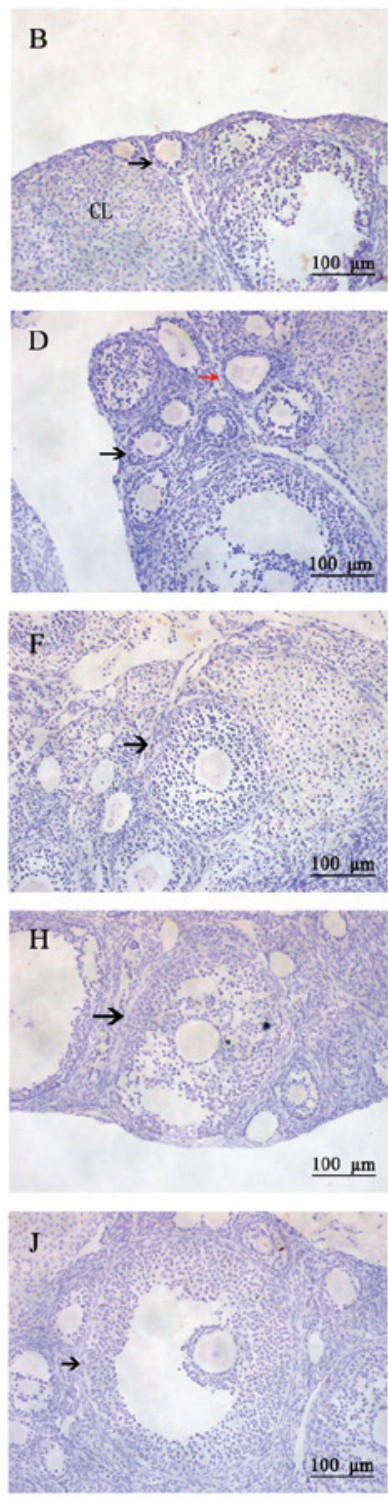

Figure 1. Immunohistochemical localization of the expression of AMH in different follicular stages. Histological ovarian sections (magnification, $\mathrm{x} 200$ ). Positive immunohistochemical staining of AMH in follicles at varying stages are shown on the left; negative control stains are shown on the right. Primary (A and B, black arrow), small preantral (C and D, black arrow), large preantral (E and F, black arrow), small antral (G and H, black arrow), and large antral (I and J, black arrow) follicles, corpus luteum (A and $\mathrm{B}, \mathrm{CL}$ ), atretic follicles (C and D, red arrow). Scale bar=100 $\mu \mathrm{m} . \mathrm{AMH}$, anti-mullerian hormone.

and were observed to decline on day 2 , with levels significantly lower than those observed on day $0(\mathrm{P}<0.05)$. Following the decrease on day 2, the levels of AMH increased, and peaked on day 4. With continuous administration of GnRHa, the expression of AMH decreased to a significantly lower level on day 7 , subsequent to the peak in all four treatment groups $(\mathrm{P}<0.01)$.

Effects of GnRHa on the expression of AMH in large preantral follicles. Similar to the observations in the small preantral follicles, the intensity of AMH staining was increased on day 1 
A

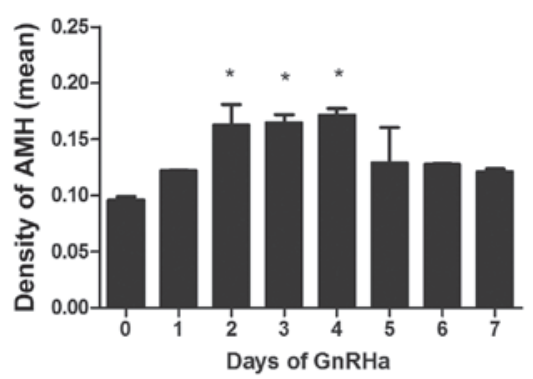

C

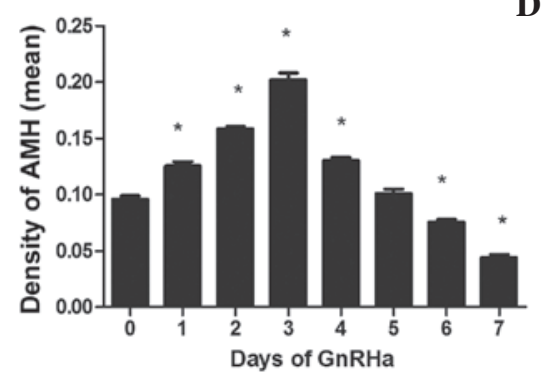

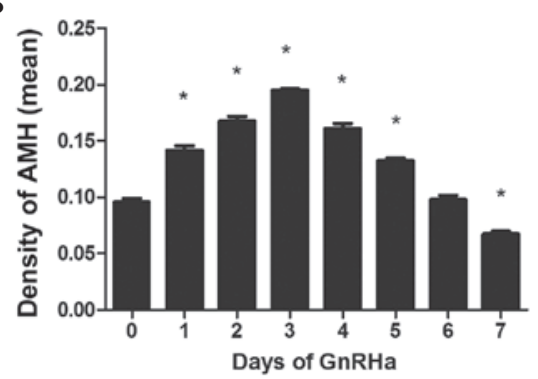

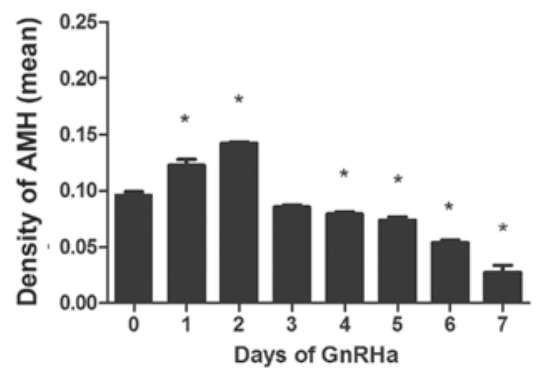

Figure 2. Time-dependent effects of GnRHa on the expression of AMH in primary follicles. The average AMH levels at (A) $1.5 \mu \mathrm{g} / 100 \mathrm{~g}$, (B) $3.0 \mu \mathrm{g} / 100 \mathrm{~g}$, (C) $4.5 \mu \mathrm{g} / 100 \mathrm{~g}$ and (D) $6.0 \mu \mathrm{g} / 100 \mathrm{~g}$ GnRHa are presented. Values are expressed as the mean \pm standard error of the mean. "P $<0.05$, compared with day 0 . $\mathrm{AMH}$, anti-mullerian hormone; GnRHa, gonadotrophin-releasing hormone agonist.

A

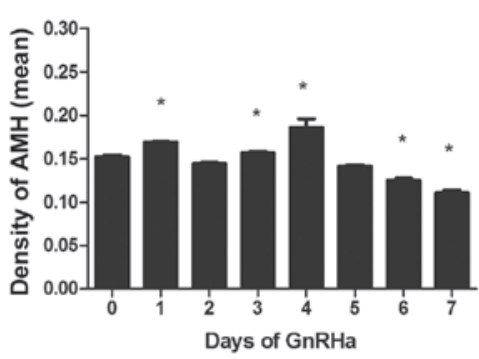

C

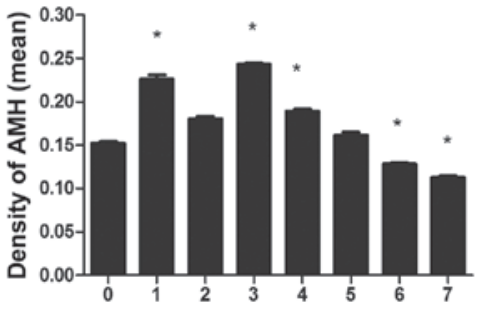

Days of GnRHa
B

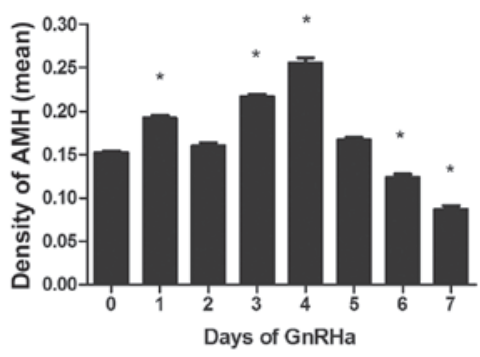

D

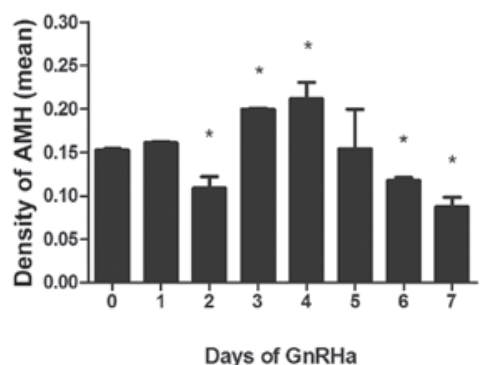

Figure 3. Time-dependent effects of GnRHa on the expression of AMH in small preantral follicles. The levels of AMH at (A) $1.5 \mu \mathrm{g} / 100 \mathrm{~g}$, (B) $3.0 \mu \mathrm{g} / 100 \mathrm{~g}$, (C) $4.5 \mu \mathrm{g} / 100 \mathrm{~g}$ and (D) $6.0 \mu \mathrm{g} / 100 \mathrm{~g}$ GnRHa are presented. Values are expressed as the mean \pm standard error of the mean. * $\mathrm{P}<0.05$, compared with day 0. $\mathrm{AMH}$, anti-mullerian hormone; GnRHa, gonadotrophin-releasing hormone agonist.

in the large preantral follicles, with a significant difference in the three lower dose groups $(\mathrm{P}<0.01)$, but no significant difference in the highest dose group $(\mathrm{P}>0.05)$. On day 2, the expression of $\mathrm{AMH}$ in all the groups reduced, compared with those on day 1, although the level of $\mathrm{AMH}$ in the lowest dose group remained significantly higher than that at day $0(\mathrm{P}<0.01$; Fig. $4 \mathrm{~A})$. The levels of $\mathrm{AMH}$ in the remaining three groups were all lower than those on day 0 , with differences becoming increasingly significant with increasing GnRHa dose. All peaks in AMH occurred on day 3. Following this peak, the levels of AMH levels declined gradually, with all groups exhibiting significantly lower levels by day 7 , compared with day 0 (all $\mathrm{P}<0.01$ ).
Effects of GnRHa on the expression of AMH expression in small antral follicles. The AMH staining observed in the GCs of the small antral follicles increased in all GnRHa treatment groups on day 1 , however, only the increase in the highest GnRHa treatment group was statistically significant to that on day 0 ( $\mathrm{P}<0.01$; Fig. 5). All treatment groups exhibited reduced expression levels of $\mathrm{AMH}$ on day 2, compared with day 0 , with the difference being significant in the two highest dose groups $(\mathrm{P}<0.05)$. The peak in expression occurred on day 4 in the three lower dose groups, and on day 3 in the highest dose group. The expression levels of AMH declined gradually following the peak in all treatment groups. The decrease on 
A

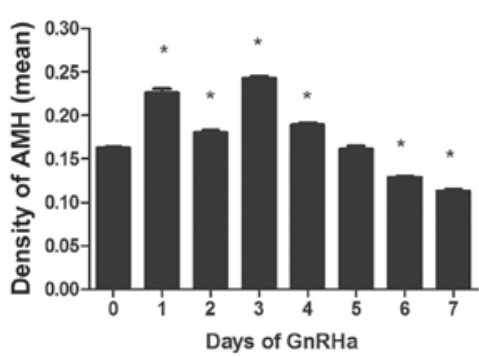

C

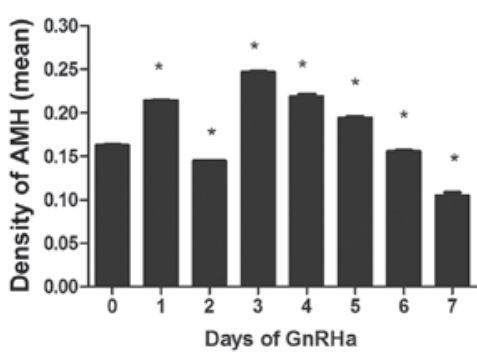

B

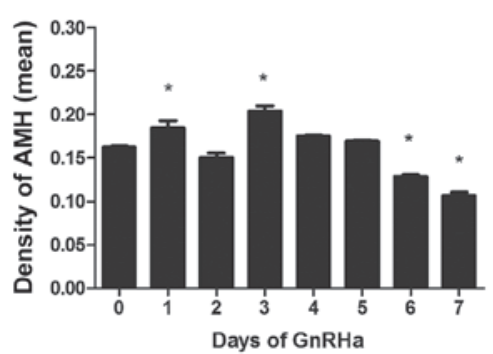

D

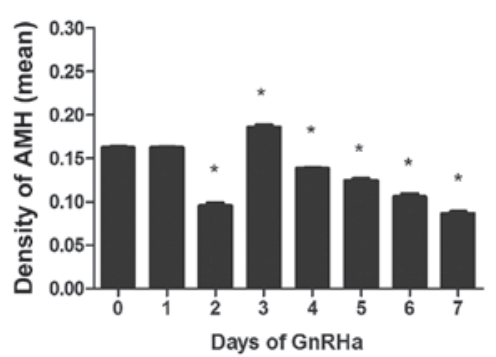

Figure 4. Time-dependent effects of GnRHa on the expression of AMH in large preantral follicles. The average AMH levels at (A) $1.5 \mu \mathrm{g} / 100 \mathrm{~g},(\mathrm{~B}) 3.0 \mu \mathrm{g} / 100 \mathrm{~g}$, (C) $4.5 \mu \mathrm{g} / 100 \mathrm{~g}$ and (D) $6.0 \mu \mathrm{g} / 100 \mathrm{~g}$ GnRHa are presented. Values are expressed as the mean \pm standard error of the mean. "P<0.05, compared with day 0 . $\mathrm{AMH}$, anti-mullerian hormone; GnRHa, gonadotrophin-releasing hormone agonist.

A

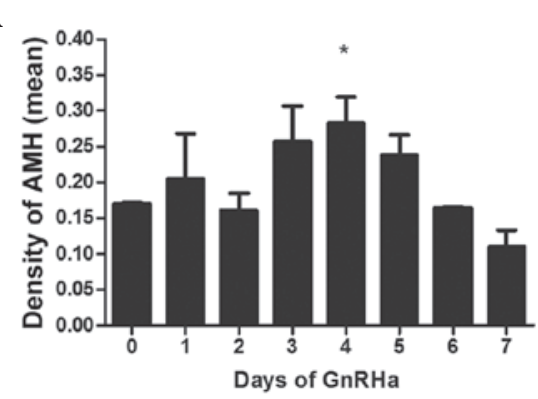

C

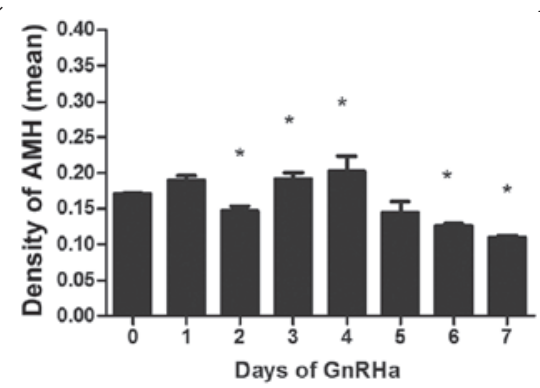

B

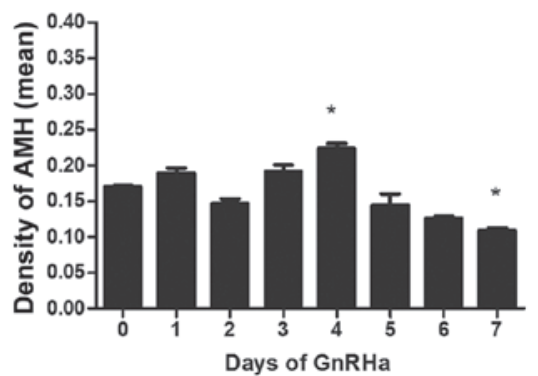

D

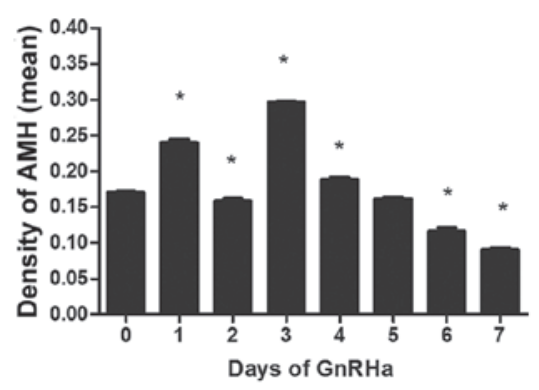

Figure 5. Time-dependent effects of GnRHa dose on AMH expression in small antral follicles. The average AMH levels at (A) $1.5 \mu \mathrm{g} / 100 \mathrm{~g},(\mathrm{~B}) 3.0 \mu \mathrm{g} / 100 \mathrm{~g}$, (C) $4.5 \mu \mathrm{g} / 100 \mathrm{~g}$ and (D) $6.0 \mu \mathrm{g} / 100 \mathrm{~g}$ GnRHa are presented. Values are expressed as the mean \pm standard error of the mean. "P<0.05, compared with day 0 . $\mathrm{AMH}$, anti-mullerian hormone; GnRHa, gonadotrophin-releasing hormone agonist.

day 7 was statistically significant, compared with day 0 , in the three highest dose groups $(\mathrm{P}<0.05)$, while no difference was observed in the lowest dose group $(\mathrm{P}>0.05)$.

Effects of GnRHa on the expression of AMH in the GCs surrounding the oocyte and basement membrane of the small antral follicles. Fig. 6 shows the changes in the expression of $\mathrm{AMH}$ in the GCs surrounding the oocyte and basement membrane. In the GCs surrounding the oocyte, a significant increase in the expression of AMH was observed on day 1 in the highest dose group only $(\mathrm{P}<0.01$; Fig. 6D). On day 2 , the intensity of $\mathrm{AMH}$ staining decreased in all groups, compared with day 1, however, the expression of $\mathrm{AMH}$ in the highest dose group was significantly higher than that on day 0 $(\mathrm{P}<0.01)$. Peak levels occurred on day 3 in all groups but the lowest dose group, which peaked on day 4 , following which the levels of AMH slowly declined. The levels of AMH in the two lowest dose groups returned to basal levels on day 7 $(\mathrm{P}>0.05)$. However, a rapid decrease resulting in a significantly lower level was observed on day 7 , compared with day 0 , in the two highest dose (all $\mathrm{P}<0.01)$.

Regarding the GCs surrounding the basement membrane, no significant changes in AMH were observed in any group on day 1. However, the two highest dose groups exhibited 
A

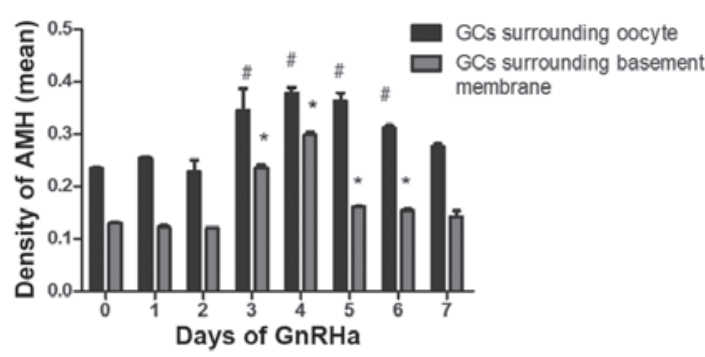

C

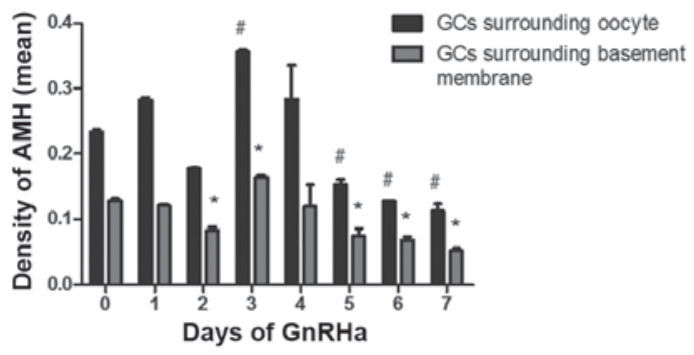

B

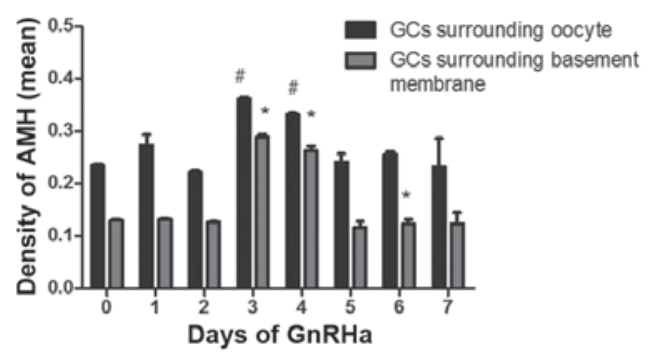

D

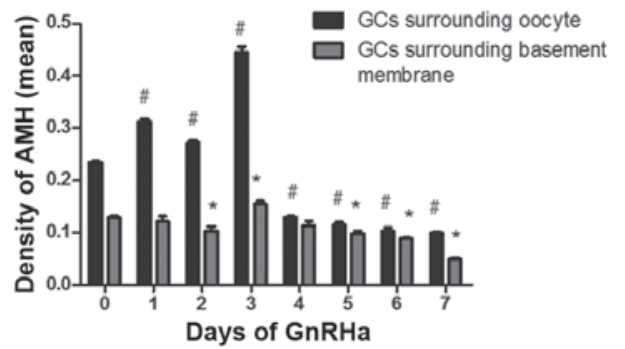

Figure 6. Time-dependent effects of GnRHa dose on the expression of AMH in the GCs surrounding the oocyte and basement membrane of small antral follicles. The average AMH levels at (A) $1.5 \mu \mathrm{g} / 100 \mathrm{~g}$, (B) $3.0 \mu \mathrm{g} / 100 \mathrm{~g}$, (C) $4.5 \mu \mathrm{g} / 100 \mathrm{~g}$ and (D) $6.0 \mu \mathrm{g} / 100 \mathrm{~g}$ GnRHa are presented. The black columns indicate the mean value of AMH in the GCs surrounding the oocyte. The grey columns indicate the mean value of AMH in the GCs surrounding the basement membrane. Values are expressed as the mean \pm standard error of the mean. ${ }^{*} \mathrm{P}<0.05$, compared with day 0 . AMH, anti-mullerian hormone; GnRHa, gonadotrophin-releasing hormone agonist; GCs, granulosa cells.

significant decreases in the expression levels of AMH on day $2(\mathrm{P}<0.05)$. The AMH peaks in the GCs surrounding the basement membrane were synchronous with those of the GCs surrounding the oocyte in all groups $(\mathrm{P}<0.05)$. In all groups, the expression of AMH declined following this peak. In the two lowest dose groups, no significant difference was observed in the AMH levels on day 7, compared with day 0 ( $\mathrm{P}>0.05)$. In the two highest dose groups, significantly lower levels were observed on day 7 , compared with those on day $0(\mathrm{P}<0.05)$.

\section{Discussion}

Serum AMH is affected by the expression of AMH in various follicular stages, however, the way in which AMH levels in the serum change during the process of downregulation remains to be fully elucidated, and reports on whether the expression of AMH in the GCs of follicles at different growing stages is affected by GnRHa in vivo are lacking. In the present study, it was demonstrated for the first time, to the best of our knowledge, that the expression of AMH in follicles at various stages change dynamically following treatment with various doses of GnRHa in vivo, during the process of downregulation.

In the mouse ovary, the present study demonstrated that the expression of AMH in follicular GCs was stage-specific. AMH protein was produced at low levels by the columnar GCs of the primary follicles, and was most abundant in the GCs of the preantral and small antral follicles. The expression of AMH was terminated in the large antral follicles and the corpora lutea, and was absent in the primordial and atretic follicles. No AMH was observed in the thecal or interstitial cells. These results are consistent with previous findings $(4,24)$. In the present study, treatment with GnRHa in vivo dids not affect the stage-specific location of the expression of AMH. In addition, it was also observed that the intensity of the expression of AMH was homogeneous in the primary follicle GCs, but heterogeneous in the preantral and small antral follicles. In primary follicles, apoptosis seldom occurs in human ovarian tissue sections (25). Similar homogeneity in the expression of AMH in all the GnRHa groups in the present study is indirectly supported by investigations performed in hypophysectomized, estrogen-treated immature rats, which suggested that GnRHa does not induce apoptosis in the GCs of primary follicles (26). However, in follicles between the small preantral and small antral stages, physical apoptosis, along with the proliferation of granulosa cells and GnRHa induce pharmacological apoptosis by binding GnRH receptors.

In the present study, the expression of AMH expressions exhibited a similar dynamic change in all follicular stages all treatment groups, with the exception of the decrease observed on day 2 from the small preantral stages onward. The levels of AMH were observed to initally increase, and then gradually decrease. The peak of AMH occured on $\sim$ day 3. GnRHa decreased the levels of AMH below their initial levels by day 7 , which occurred in a dose-dependent manner. Furthermore, from the peak onwards, the expression of AMH declined in a time-dependent manner. In general, the AMH profile in the GCs of the small antral follicles was similar to that of preantral the follicles. It is evident that antrum formation physically demarcates the former preantral GCs into mural and cumulus GC populations (27). Notably, the present study demonstrated that the time-dependent dynamic changes in the expression of AMH in the GCs from the two different regions were different. Firstly, the AMH profile in GCs surrounding the oocyte was similar to that of the preantral follicles, while a marked difference was observed in the GCs surrounding the basement membrane, particularly on the first day of GnRHa administration, without a visible increase. This result confirmed that of a previous finding that cumulus cells are more closer associated with preantral GCs, compared with mural granulosa cells (28). Secondly, the expression of AMH in the small antral follicles 
was more abundant in the GCs surrounding the oocyte than in the GCs within the basement membrane, which was consistent with previous findings $(5,24)$. The difference in AMH intensity indirectly demonstrated functional differences between the GCs in different locations. Follicle-stimulating hormone receptor (FSHR) is highly expressed in cumulus cells. By binding FSHR, FSH can induce the expansion of cumulus cells and is involved in oocyte maturation (29). In addition, it has been reported that the expression levels of FSHR and AMHR2 in cumulus cells is associated with the expression of $\mathrm{AMH}$ (30). Therefore, the response to FSH is more marked in GCs surrounding the oocyte than in the basement membrane, which partly explains their more visible ascent on day 1 in all groups surrounding the oocyte.

During the first few days of the downregulation, daily injection GnRHa causes an initial flare-up of gonadotropin concentration by acting at the level of the hypothalamo-hypophysis axis. Following this increase, the pituitary gland is downregulated to a hypogonadotropic state (31). Therefore, under the effects of GnRHa, gonadotropins first increase and then slowly decrease. Previous studies have demonstrated this dynamic change in FSH, LH and E2, and observed an increasing tendency on day 3 when GnRHa was administrated to rats (32). In the present study, a similar increasing tendency of AMH around day 3 was observed. Accordingly, the present study hypothesized that the expression of AMH is, at least partially, gonadotropin-dependent. This hypothesis is supported further by previous in vitro findings demonstrating the stimulation of AMH production in GCs following the addition of FSH (33). Similarly, experiments performed in primates also support a possible positive role for gonadotropins in the regulation of AMH (34). By contrast, other studies have revealed that $\mathrm{FSH}$ may downregulate the expression of AMH (19,24). Therefore, controversies exist regarding the effect of gonadotropins on the expression of AMH, although early investigations have reported that the expression of $\mathrm{AMH}$ is gonadotropin-independent $(35,36)$.

Indirectly, the results of the present study suggested that the production of AMH in primary follicles is partially gonadotropin-responsive. Supporting this hypothesis are previous findings that FSH and LH receptor mRNAs exist in primary follicles $(37,38)$. The time-dependent changes observed in the expression of AMH in preantral and small antral follicles were not entirely in accordance with the trend of gonadotropins, particularly on day 2, therefore, the production of AMH was not only positively regulated by gonadotropins, but also negatively regulated by other factors.

GnRHa acts predominantly on the hypothalamus-pituitary-gonad axis by inducing a hypogonadotropic milieu from continuous exposure to the agent. Apart from its pituitary actions, several studies have demonstrated that GnRHa can exert effects on the ovary in an autocrine-paracrine manner, as an intra-ovarian regulatory factor, particularly by affecting follicular development and steroidogenesis $(39,40)$. This direct GnRHa effect on the ovary is supported by increasing evidence that GnRH receptors exist in ovarian tissue $(39,41-46)$. One of the direct actions on the ovary is inhibition of the expression of gonadotropin receptors in granulosa cells (47). These findings suggest that the anti-gonadotropic effect by GnRHa contributes to the reduction of AMH. The results of a previous study revealed that lower levels of AMH in intrafollicular fluid are found in females treated with GnRHa (21). According to previous studies, GnRHa directly inhibits proliferative activity and induces apoptosis in GCs from preantral and small antral follicles $(21,26,48)$, and the incidence of apoptosis increases in a dose-dependent manner (49). Other studies have reported that the expression of $\mathrm{AMH}$ is associated with the proliferation of GCs (5). The present study hypothesized that the downregulation of the expression of AMH by GnRHa results from an inhibitory effect of mitotic activity and induction of apoptosis, although the mechanisms remain to be elucidated.

In the present study, the protein expression pattern of AMH in primary follicles on day 2 was different from that of the preantral and small antral follicles. The discrepancy in the density of $\mathrm{GnRH}$ receptors may, at least in part, explain this difference, GnRH receptors have been reported to localize in granulosa cells of the preantral and small antral follicles, whereas no GnRH receptors exist in primary follicles (45). The present study hypothesized that the positive effects of FSH on the expression of AMH expression were partially counteracted by the negative effects of GnRHa through acting on GnRH receptors, leading to a significant decrease in the levels of $\mathrm{AMH}$ on day 2 in the preantral and antral follicles. In preovulatory rat GCs, GnRH induces an increase in the receptor levels in a dose-dependent manner (50). This may partly explain the finding that the expression of $\mathrm{AMH}$ in the preantral and small antral follicles was lowest at the end of downregulation in the group treated with the highest dose of GnRHa. As for the degree of decrease in the expression of $\mathrm{AMH}$ in the GCs surrounding the oocyte and basement membrane of the small antral follicles, GnRH receptors may explain this discrepancy. An increased density of GnRH receptors exist in the cumulus cells surrounding the oocyte, compared with mural GCs (45). Therefore, inhibition of AMH by GnRHa may be higher in GCs surrounding the oocyte.

During the process of downregulation to induce a hypogonadotropic state, GnRHa causes an initial 'flare-up' effect, resulting in a transitory increase of gonadotrophins. This effect accelerates follicle recruitment (51). In addition, it is now evident that $\mathrm{AMH}$ is involved in mouse primordial follicle selection $(9,52)$, and growing follicle cyclic recruitment in humans (8) and mice (53). AMH inhibits FSH-stimulated follicle growth by decreasing the responsiveness of the follicle to FSH $(53,54)$. The inhibitory effect of AMH on the expression of aromatase activity and $\mathrm{LH}$ receptors by cultured GCs is also in agreement with the inhibitory effect on follicle growth (55). Therefore, it was suggested that the decrease of AMH observed in the present study on day 2 accelerated follicle recruitment, while the increase of $\mathrm{AMH}$ around the peak day restricted further follicular development in an autocrine-paracrine manner. Following the the 'flare-up,' FSH decreases gradually. In the hypogonadotropic state, follicle development is relatively static. The low expression levels of AMH on day 7 may have been associated with increased sensitivity to FSH, allowing follicles to be selected synchronously for continued growth by exogenous application of gonadotrophins. This suggested that AMH may be one of the factors involved in follicular synchronicity.

Follicular development is a process not only regulated by the hypothalamic-pituitary-ovarian axis, but is also affected 
by autocrine/paracrine factors of the ovaries (51). A bidirectional communication between oocytes and GCs contributes to follicular development (56). The oocyte itself has effects on gene expression and protein synthesis in the GCs by secreting paracrine factors, and GCs regulate oocyte developmental competence (57). Treatment of GnRHa in vivo may affect the communication between the oocyte and GCs, by either changing the function of the GCs or modulating the response of GCs to paracrine factors secreted by the oocyte, leading to changes in the expression of $\mathrm{AMH}$. The expression and secretion of AMH by cumulus GCs is correlated with oocyte maturity, with an inverse association between the expression of AMH and oocyte maturity (58). This suppression of oocyte maturation by AMH has been demonstrated previously (59). In addition, observations from the rat model also support this inhibitory role of AMH (60). Therefore, the downregulation of AMH observed on day 7 in the presents study may be a marker of oocyte quality, and it was hypothesized that appropriate treatment with GnRHa in vivo may improve oocyte quality. Consistent with this hypothesis, a previous study performed in the mice demonstrated that administrating GnRH in addition to the standard pregnant mare serum gonadotropin (PMSG) and human chorionic gonadotropin (hCG) treatments improves IVF fertility rate, compared with standard treatments (61). This further supports the possibility that GnRHa in vivo may regulate follicle development and improve oocyte quality through changes in the expression of $\mathrm{AMH}$ during the process of downregulation.

The present study demonstrated that treatment of GnRHa in vivo affects the expression of $\mathrm{AMH}$ in follicles at different stages in the ovaries of cycling mice during the process of downregulation, however it has no affect on its expression pattern. The effect of GnRHa on the expression of AMH was dose-dependent. The dynamic changes observed in the expression of AMH in the present study may contribute to the use of GnRHa in regulating follicle development and improving oocyte quality during downregulation in assisted reproductive technology. However, the potential mechanisms underlying the daily fluctuations in the expression of AMH caused by GnRHa in vivo requires further investigation.

\section{Acknowledgements}

This study was sponsored by the Shantou University Medical College Clinical Research Enhancement Initiative and the National Natural Science Foundation of China (grant. nos. 81070542 and 30872771 ). The authors would like to thank Dr Xin Zhang for their advice, and the faculty and staff from the Laboratory of Molecular Cardiology of the First Affiliated Hospital of Shantou University Medical College, for their assistance with histological examination.

\section{References}

1. Cate RL, Hession C, Tizard R, Farber NM, Cheung A, Ninfa EG, Frey AZ, Gash DJ, Chow EP and Mattaliano RJ: Isolation of the bovine and human genes for Müllerian inhibiting substance and expression of the human gene in animal cells. Cell 45: 685-698, 1986.

2. Massague J: The transforming growth factor-beta family. Annu Rev Cell Biol 6: 597-641, 1990.
3. Vigier B, Picard JY, Tran D, Legeai L and Josso N: Production of anti-Müllerian hormone: another homology between Sertoli and granulosa cells. Endocrinology 114: 1315-1320, 1984.

4. Munsterberg A and Lovell-Badge R: Expression of the mouse anti-müllerian hormone gene suggests a role in both male and female sexual differentiation. Development 113: 613-624, 1991.

5. Hirobe S, He WW, Lee MM and Donahoe PK: Mullerian inhibiting substance messenger ribonucleic acid expression in granulosa and sertoli cells coincides with their mitotic activity. Endocrinology 131: 854-862, 1992.

6. Ueno S, Takahashi M, Manganaro TF, Ragin RC and Donahoe PK: Cellular localization of müllerian inhibiting substance in the developing rat ovary. Endocrinology 124: 1000-1006, 1989.

7. Bézard J, Vigier B, Tran D, Mauléon P and Josso N: Anti-müllerian hormone in sheep follicles. Reprod Nutr Dev 28: 1105-1112, 1988.

8. Weenen C, Laven JS, Von Bergh AR, Cranfield M, Groome NP, Visser JA, Kramer P, Fauser BC and Themmen AP: Anti-Müllerian hormone expression pattern in the human ovary: Potential implications for initial and cyclic follicle recruitment. Mol Hum Reprod 10: 77-83, 2004.

9. Durlinger AL, Gruijters MJ, Kramer P, Karels B, Ingraham HA, Nachtigal MW, Uilenbroek JT, Grootegoed JA and Themmen AP: Anti-Mullerian hormone inhibits initiation of primordial follicle growth in the mouse ovary. Endocrinology 143: 1076-1084, 2002.

10. Durlinger AL, Kramer P, Karels B, de Jong FH, Uilenbroek JT, Grootegoed JA and Themmen AP: Control of primordial follicle recruitment by anti-Müllerian hormone in the mouse ovary. Endocrinology 140: 5789-5796, 1999.

11. Ha TU, Segev DL, Barbie D, Masiakos PT, Tran TT, Dombkowski D, Glander M, Clarke TR, Lorenzo HK, Donahoe PK, et al: Mullerian inhibiting substance inhibits ovarian cell growth through an Rb-independent mechanism. J Biol Chem 275: 37101-37109, 2000.

12. di Clemente N, Ghaffari S, Pepinsky R, Pieau C, Josso N, Cate RL and Vigier B: A quantitative and interspecific test for biological activity of anti-mullerian hormone: The fetal ovary aromatase assay. Development 114: 721-727, 1992.

13. Teixeira J, Maheswaran S and Donahoe PK: Müllerian inhibiting substance: An instructive developmental hormone with diagnostic and possible therapeutic applications. Endocr Rev 22: 657-674, 2001.

14. Visser JA, de Jong FH, Laven JS and Themmen AP: Anti-Müllerian hormone: A new marker for ovarian function. Reproduction 131: 1-9, 2006.

15. Metallinou C, Asimakopoulos B, Schröer A and Nikolettos N: Gonadotropin-releasing hormone in the ovary. Reprod Sci 14: 737-749, 2007.

16. Schmutzler R, Reichert C, Diedrich K, Wildt L, Diedrich C, Al-Hasani S, van der Ven $\mathrm{H}$ and Krebs D: Combined GnRH-agonist/gonadotrophin stimulation for in-vitro fertilization. Hum Reprod 3: 29-33, 1988.

17. Mohamed KA, Davies WA and Lashen H: Antimüllerian hormone and pituitary gland activity after prolonged down-regulation with goserelin acetate. Fertil Steril 86: 1515-1517, 2006.

18. Hagen CP, Sørensen K, Anderson RA and Juul A: Serum levels of antimüllerian hormone in early maturing girls before, during and after suppression with GnRH agonist. Fertil Steril 98: 1326-1330, 2012

19. Anderson RA, Themmen AP, Al-Qahtani A, Groome NP and Cameron DA: The effects of chemotherapy and long-term gonadotrophin suppression on the ovarian reserve in premenopausal women with breast cancer. Hum Reprod 21: 2583-2592, 2006.

20. Winkler N, Bukulmez O, Hardy DB and Carr BR: Gonadotropin releasing hormone antagonists suppress aromatase and anti-Müllerian hormone expression in human granulosa cells. Fertil Steril 94: 1832-1839, 2010.

21. Seifer DB, MacLaughlin DT, Penzias AS, Behrman HR, Asmundson L, Donahoe PK, Haning RV Jr and Flynn SD: Gonadotropin-releasing hormone agonist-induced differences in granulosa cell cycle kinetics are associated with alterations in follicular fluid müllerian-inhibiting substance and androgen content. J Clin Endocrinol Metab 76: 711-714, 1993.

22. Britt KL, Saunders PK, McPherson SJ, Misso ML, Simpson ER and Findlay JK: Estrogen actions on follicle formation and early follicle development. Biol Reprod 71: 1712-1723, 2004.

23. Pelusi C, Ikeda Y, Zubair M and Parker KL: Impaired follicle development and infertility in female mice lacking steroidogenic factor 1 in ovarian granulosa cells. Biol Reprod 79: 1074-1083, 2008 . 
24. Baarends WM, Uilenbroek JT, Kramer P, Hoogerbrugge JW, van Leeuwen EC, Themmen AP and Grootegoed JA: Anti-müllerian hormone and anti-müllerian hormone type II receptor messenger ribonucleic acid expression in rat ovaries during postnata development, the estrous cycle and gonadotropin-induced follicle growth. Endocrinology 136: 4951-4962, 1995.

25. Takekida S, Matsuo H and Maruo T: GnRH agonist action on granulosa cells at varying follicular stages. Mol Cell Endocrinol 202: 155-164, 2003.

26. Billig H, Furuta I and Hsueh AJ: Gonadotropin-releasing hormone directly induces apoptotic cell death in the rat ovary: Biochemical and in situ detection of deoxyribonucleic acid fragmentation in granulosa cells. Endocrinology 134: 245-252, 1994.

27. Diaz FJ, Wigglesworth K and Eppig JJ: Oocytes are required for the preantral granulosa cell to cumulus cell transition in mice. Dev Biol 305: 300-311, 2007.

28. Erickson GF, Hofeditz C, Unger M, Allen Wr and Dulbecco R: A monoclonal antibody to a mammary cell Line recognizes two distinct subtypes of ovarian granulosa cells*. Endocrinology 117: 1490-1499, 1985.

29. Kawashima I, Okazaki T, Noma N, Nishibori M, Yamashita Y and Shimada M: Sequential exposure of porcine cumulus cells to FSH and/or LH is critical for appropriate expression of steroidogenic and ovulation-related genes that impact oocyte maturation in vivo and in vitro Reproduction 136: 9-21, 2008.

30. Grøndahl ML, Nielsen ME, Dal Canto MB, Fadini R, Rasmussen IA, Westergaard LG, Kristensen SG and Yding Andersen C: Anti-Müllerian hormone remains highly expressed in human cumulus cells during the final stages of folliculogenesis Reprod Biomed Online 22: 389-398, 2011.

31. Albuquerque LE, Tso LO, Saconato H, Albuquerque MC and Macedo CR: Depot versus daily administration of gonadotrophin-releasing hormone agonist protocols for pituitary down regulation in assisted reproduction cycles. Cochrane Database Syst Rev 1: CD002808, 2013

32. Li X, Kang X, Deng Q, Cai J and Wang Z: Combination of a GnRH agonist with an antagonist prevents flare-up effects and protects primordial ovarian follicles in the rat ovary from cisplatin-induced toxicity: A controlled experimental animal study. Reprod Biol Endocrinol 11: 16, 2013.

33. Taieb J, Grynberg M, Pierre A, Arouche N, Massart P, Belville C, Hesters L, Frydman R, Catteau-Jonard S, Fanchin R, et al: FSH and its second messenger cAMP stimulate the transcription of human anti-Müllerian hormone in cultured granulosa cells. Mol Endocrinol 25: 645-655, 2011.

34. Thomas FH, Telfer EE and Fraser HM: Expression of anti-Mullerian hormone protein during early follicular development in the primate ovary in vivo is influenced by suppression of gonadotropin secretion and inhibition of vascular endothelial growth factor. Endocrinology 148: 2273-2281, 2007.

35. Fanchin R, Taieb J, Lozano DH, Ducot B, Frydman R and Bouyer J: High reproducibility of serum anti-Müllerian hormone measurements suggests a multi-staged follicular secretion and strengthens its role in the assessment of ovarian follicular status. Hum Reprod 20: 923-927, 2005.

36. Fanchin R, Schonäuer LM, Righini C, Frydman N, Frydman R and Taieb J: Serum anti-Müllerian hormone dynamics during controlled ovarian hyperstimulation. Hum Reprod 18: 328-332, 2003.

37. Patsoula E, Loutradis D, Drakakis P, Michalas L, Bletsa R and Michalas S: Messenger RNA expression for the follicle-stimulating hormone receptor and luteinizing hormone receptor in human oocytes and preimplantation-stage embryos. Fertil Steril 79: 1187-1193, 2003

38. Oktay K, Briggs D and Gosden RG: Ontogeny of follicle-stimulating hormone receptor gene expression in isolated human ovarian follicles 1. J Clin Endocrinol Metab 82: 3748-3751, 1997.

39. Janssens RM, Brus L, Cahill DJ, Huirne JA, Schoemaker J and Lambalk CB: Direct ovarian effects and safety aspects of $\mathrm{GnRH}$ agonists and antagonists. Hum Reprod Update 6: 505-518, 2000.

40. Kang SK, Cheng KW, Nathwani PS, Choi K-C and Leung PC: Autocrine role of gonadotropin-releasing hormone and its receptor in ovarian cancer cell growth. Endocrine 13: 297-304, 2000.

41. Stojilkovic SS, Reinhart J and Catt KJ: Gonadotropin-releasing hormone receptors: Structure and signal transduction pathways. Endocr Rev 15: 462-499, 1994
42. Hsueh AJ and Jones PB: Extrapituitary actions of gonadotropin-releasing hormone. Endocr Rev 2: 437-461, 1981.

43. Schirman-Hildesheim TD, Ben-Aroya N and Koch Y: Daily $\mathrm{GnRH}$ and GnRH-receptor mRNA expression in the ovariectomized and intact rat. Mol Cell Endocrinol 252: 120-125, 2006.

44. Schirman-Hildesheim TD, Bar T, Ben-Aroya N and Koch Y: Differential gonadotropin-releasing hormone $(\mathrm{GnRH})$ and $\mathrm{GnRH}$ receptor messenger ribonucleic acid expression patterns in different tissues of the female rat across the estrous cycle. Endocrinology 146: 3401-3408, 2005.

45. Singh P, Krishna A, Sridaran $R$ and Tsutsui K: Immunohistochemical localization of $\mathrm{GnRH}$ and RFamide-related peptide- 3 in the ovaries of mice during the estrous cycle. J Mol Histol 42: 371-381, 2011.

46. Torrealday S, Lalioti MD, Guzeloglu-Kayisli O and Seli E: Characterization of the gonadotropin releasing hormone receptor (GnRHR) expression and activity in the female mouse ovary. Endocrinology 154: 3877-3887, 2013.

47. Ranta T, Knecht M, Baukal AJ, Korhonen M and Catt KJ: GnRH agonist-induced inhibitory and stimulatory effects during ovarian follicular maturation. Mol Cell Endocrinol 35: 55-63, 1984.

48. Parborell F, Pecci A, Gonzalez O, Vitale A and Tesone M: Effects of a gonadotropin-releasing hormone agonist on rat ovarian follicle apoptosis: Regulation by epidermal growth factor and the expression of Bcl-2-related genes. Biol Reprod 67: 481-486, 2002.

49. Park EJ, Shin JW, Seo YS, Kim DW, Hong SY, Park WI and Kang BM: Gonadotropin-releasing hormone-agonist induces apoptosis of human granulosa-luteal cells via caspase- $8,-9$ and -3 and poly-(ADP-ribose)-polymerase cleavage. Biosci Trends 5: 120-128, 2011.

50. Yu B, Ruman J and Christman G: The role of peripheral gonadotropin-releasing hormone receptors in female reproduction. Fertil Steril 95: 465-473, 2011.

51. Dong M, Huang L, Wang W, Du M, He Z, Mo Y and Yang D: Regulation of AMH and SCF expression in human granulosa cells by GnRH agonist and antagonist. Pharmazie 66: 436-439, 2011.

52. McGee EA and Hsueh AJ: Initial and cyclic recruitment of ovarian follicles. Endocr Rev 21: 200-214, 2000.

53. Durlinger AL, Kramer P, Karels B, Kumar TR, Matzuk MM, Rose UM, de Jong FH, Uilenbroek JT, Grootegoed JA, Themmen AP, et al: Anti-Müllerian hormone attenuates the effects of FSH on follicle development in the mouse ovary. Endocrinology 142: 4891-4899, 2001.

54. Pellatt L, Rice S, Dilaver N, Heshri A, Galea R, Brincat M, Brown K, Simpson ER and Mason HD: Anti-Müllerian hormone reduces follicle sensitivity to follicle-stimulating hormone in human granulosa cells. Fertil Steril 96: 1246-1251. 2011

55. di Clemente N, Goxe B, Remy JJ, Cate RL, Josso N and Vigier B and Salesse R: Inhibitory effect of AMH upon the expression of aromatase activity and LH receptors by cultured GCsof rat and porcine immature ovaries. Endocrine 2: 553-558, 1994.

56. Eppig JJ: Oocyte control of ovarian follicular development and function in mammals. Reproduction (Cambridge, England) 122 829-838, 2001

57. Devjak R1, Fon Tacer K, Juvan P, Virant Klun I, Rozman D and Bokal E: Cumulus cells gene expression profiling in terms of oocyte maturity in controlled ovarian hyperstimulation using GnRH agonist or GnRH antagonist. PLoS One 7: e47106, 2012.

58. Kedem-Dickman A, Maman E, Yung Y, Yerushalmi GM, Hemi R, Hanochi M, Dor J and Hourvitz A: Anti-Müllerian hormone is highly expressed and secreted from cumulus granulosa cells of stimulated preovulatory immature and atretic oocytes. Reprod Biomed Online 24: 540-546, 2012

59. Cook CL, Siow Y, Taylor S and Fallat ME: Serum müllerian-inhibiting substance levels during normal menstrual cycles. Fertil Steril 73: 859-861, 2000

60. Lee MM and Donahoe PK: Mullerian inhibiting substance: A gonadal hormone with multiple functions. Endocr Rev 14 152-164, 1993.

61. Vasudevan K and Sztein JM: In vitro fertility rate of 129 strain is improved by buserelin (gonadotropin-releasing hormone) administration prior to superovulation. Lab Anim 46: 299-303, 2012. 